\title{
Antibacterial Efficacy Analysis of Ricinus communis, Senna auriculata and Euphorbia hirta Extract Treated on the Four Variant of Denim Fabric against Escherichia coli and Staphylococcus aureus
}

\author{
M.Sumithra ${ }^{1 *}$ and N.Vasugi Raaja ${ }^{2}$
}

${ }^{1}$ Assistant Professor, Department of Costume Design and Fashion, PSG College of Arts and Science, Civil Aerodrome Post, Coimbatore-641014 ${ }^{2}$ Professor \& HOD, Department of Textiles and clothing, Avinashilingam Deemed University, Coimbatore

\begin{abstract}
In the present study the methanol extracts of Ricinus communis, Senna auriculata and Euphorbia hirta were screened for their antimicrobial efficiency and the combinations (1:3:2) and the condition $20 \mathrm{kgf} / \mathrm{cm}^{2}$ Pressure, $20 \mathrm{~m} /$ min rpm were standardized for the selected herbs. The herbal extracts were applied on the four variant of denim fabric directly by using dip method. The antimicrobial activity of the finished fabrics was assessed against bacteria that normally exist like Escherichia coli and staphylococcus aureus. To enhance the durability of the finished fabric, micro encapsulation and nano encapsulation of the herbal extracts were performed and the results showed good resistance for microbes.
\end{abstract}

Keywords: Antimicrobial; Denim fabric; Medicinal herbs; Micro encapsulation; Nano encapsulation

\section{Introduction}

These natural antimicrobial substances are not only eco-friendly but also from renewable sources. Bacteria and fungi are microbes that can grow on textiles. Microbial growth, especially bacteria, in textile materials can result in the deterioration of fabric properties, development of foul smells, skins irritation and cross infections. Following are the functions of antimicrobial finishes,

1 To avoid cross infection by pathogenic microorganisms.

2 To control the infestation by microbes

3 To arrest metabolism in microbes in order to reduce the odor formation

4 To safeguard the textile products from staining, discoloration and quality deterioration [1].

The application of antimicrobial textile finishes includes a wide range of textile products [2]. Fungi, molds or mildew are complex organisms with slow growth rate. They stain the fabric and deteriorate the performance properties of the fabrics. So to make the environment healthy, hygienic and fresh, it becomes very important to have the control over growth of the microbes. Antimicrobial finishes have increased its importance in the recent years for several reasons. They serve the consumer by offering protection from the harmful effects of certain microbes [3].

Applications of micro encapsulation include controlled release of the active components, particle coating, flavor stabilization, taste masking, physical/chemical stabilization and improvement of shelf life and prevention of exposure of the active material to the surroundings [4]. Two common technologies can be used to obtain such Nano capsules and microcapsules the interfacial polymerization of a monomer or the interfacial deposition of a preformed polymer [5].

The nanotechnology applied in textile industry is still recent. Worldwide forums directed to textile manufacturers about nanotechnology are happening the understanding of the purpose of this science. By this way the nanotechnology let fabrics to obtain special properties like: anti-microbial, anti-UV, self-cleaning, nanocapsules of moisturizing agents, deodorizing, repellent and others. This potential on textiles has increased continually, because the commercialization of nanotechnology continues to grow worldwide [6].

Denim the favorite fabric for youngsters has indeed come a long way. The scopes of denim were increasing tremendously every where [7]. Denim has gained much popularity that if you look around, you will surely notice somebody wearing denim in your nearby. Now, more than just complementing a rugged style, the denim has become suitable for any occasion [8] So in the present investigation aims at developing an eco friendly natural antimicrobial finish from plant extracts for textile application. The objectives for this study are

${ }^{*}$ To screen for the functional properties from the natural herbs

${ }^{*}$ To standardize the effective herbal combination and conditions for the functional activities

${ }^{*}$ To evaluate the functional activities of the finished fabrics

*Micro encapsulation and Nano encapsulation techniques used to increase the durability of the antimicrobial finish

\section{Materials and Methods}

\section{Materials}

The fabric was sourced from the market with respect to the expected quality requirements. The fabric chosen for the study are

*Corresponding author: M. Sumithra, Assistant Professor, Department of Costume Design and Fashion, PSG College of Arts and Science, Civil Aerodrome Post, Coimbatore-641014; E-mail: mithrasumi6@rediffmail.com

Received February 23, 2012; Accepted March 12, 2012; Published March 15 2012

Citation: Sumithra M, Vasugi Raaja N (2012) Antibacterial Efficacy Analysis of Ricinus communis, Senna auriculata and Euphorbia hirta Extract Treated on the Four Variant of Denim Fabric against Escherichia coli and Staphylococcus aureus. J Textile Sci Engg 2:111. doi:10.4172/2165-8064.1000111

Copyright: @ 2012 Sumithra M, et al. This is an open-access article distributed under the terms of the Creative Commons Attribution License, which permits unrestricted use, distribution, and reproduction in any medium, provided the original author and source are credited. 
Citation: Sumithra M, Vasugi Raaja N (2012) Antibacterial Efficacy Analysis of Ricinus communis, Senna auriculata and Euphorbia hirta Extract Treated on the Four Variant of Denim Fabric against Escherichia coli and Staphylococcus aureus. J Textile Sci Engg 2:111. doi:10.4172/21658064.1000111

Sample A- $68 \%$ cotton $+32 \%$ polyester, square weight- 264.2 (Twill weave).

Sample B- $68 \%$ cotton $+32 \%$ polylycra ( $27 \%$ polyester and $5 \%$ lycra), square weight-246.4(Twill weave)

Sample C-68\% cotton $+32 \%$ corespun Lycra (27\% core spun and $5 \%$ lycra), square weight-262.2(Twill weave) and

Sample D-100\% cotton, square weight-219.4(Twill weave)

The above samples were dyed with indigo dye, no softener is used and pre treated with hot water before finishing.

\section{Methods}

Preparation of herbal extracts: The collected plants were dried with in a temperature range of $100-140^{\circ} \mathrm{F}$ as they cannot be stored without drying so that the breakdown of important compounds and contamination by microorganisms can be avoided Garbling, the separation of that portion of the plant to be used from other parts of the plants, dirt and other extraneous matter was done manually by hand. Grinding or mincing of the leaves was carried out in a mixie. The fine powder obtained after grinding was used for extraction. Each $100 \mathrm{~g}$ of the powdered plant material was refluxed in a Sox let apparatus in $1000 \mathrm{ml}$ of methanol. After overnight incubation, the supernatant was filtered through what man no.1 filter paper and the filtrate was dried to evaporate the organic solvent at room temperature.

Finishing of the herbal extracts on the denim fabric: The denim fabric purchased from K.G. Denim Ltd, Coimbatore was used for the present study. The fabric sample was given a primary wash with distilled water, air-dried and then used for herbal finishing. The fabric was finished with herbal extract by dip method. The fabric was immersed in the extract for 30 mins and then air-dried. The finished fabric was used for the antibacterial assessment using standard bacterial strains.

Evaluation of antibacterial activity by The American Association of Textile Chemists and Colorists 147 test method

From the preliminary screening, the herbal extracts with antibacterial activity were mixed in various combinations and conditions screened for their Combinatorial Antibacterial property by AATCC 147 test method. The AATCC Plates were prepared by pouring $15 \mathrm{ml}$ of AATCC media in to sterile Petri plates. The plates were allowed to solidify for 5 minutes and $0.1 \%$ inoculums suspension of The isolated wound predominates were swabbed uniformly and the inoculums was Allowed to dry for 5minutes. The herbal extract finished denim fabric with theDiameter of $23 \mathrm{~mm}$ was placed on the surface of medium and the plates were kept for incubation at $37^{\circ} \mathrm{C}$ for 24 hours. At the end of incubation, zone of inhibition formedAround the fabric was ensured in millimeter and recorded. Plants used in the present study have been shown in Table 1.

\section{Micro encapsulation of herbal extracts}

Microcapsules containing herbal extract were formed by the addition of sodium alginate followed by spraying into the calcium chloride solution by means of a sprayer. The droplets were retained in the calcium chloride solution for 15 minutes for hardening of the capsules. The microcapsules were obtained by decantation and followed by repeated washing with isopropyl alcohol and by drying at $45^{\circ} \mathrm{C}$ for 12 hours. The microcapsules were finished on the fabric by exhaustion method with the following composition. $8 \%$ citric acid was used as cross-linking agent. The fabric was kept immersed in the solution (ML ratio - 1: 20) for 30 minutes at $50^{\circ} \mathrm{C}$ in water bath. After finishing, the fabric was removed, squeezed and dried at $80^{\circ} \mathrm{C}$ in the oven for 5 minutes and then cured at $120^{\circ} \mathrm{C}$ for 2 minutes. The antibacterial activity of the microcapsule-finished fabric was analyzed by AATCC 147 test method.

\section{Nano encapsulation of herbal extracts}

Selection of wall and core material: The herbal extracts prepared were encapsulated using bovine albumin fraction as the wall material and the Nano particles as the core material.

\section{Procedure}

The herbal extract enclosed bovine serum albumin protein was prepared by coacervation process followed by cross-linking with glutaraldehyde. After glutaraldehyde treatment, for purification the solution is put in rotary vaccum evaporator to remove the organic solvent and then centrifuged at 4 degree celsius at 10,000 rpm and then suspended in $0.1 \mathrm{M}$ phosphate buffer ( $\mathrm{pH}$ 7.4). Then Lyophilized with mannitol $(2 \% \mathrm{w} / \mathrm{V})$.The herbal extract was incubated with the required protein solution $(2 \% \mathrm{~W} / \mathrm{V})$ for an hour at room temperature. The $\mathrm{pH}$ of the solution was adjusted to 5.5 by $1 \mathrm{M} \mathrm{HCL}$ using digital $\mathrm{pH}$ meter. Then ethanol was added to the solution in the ratio of 2:1 (V/V). The rate of ethanol addition was carefully controlled at $1 \mathrm{ml}$ per minute. The coacervate so formed was hardened with $25 \%$ glutaraldehyde for 2 hours to allow cross-linking of protein. Organic solvents were then removed under reduced pressure by rotary vacuum evaporator and the resulting nanocapsules were purified by centrifugation at $(10,000 \mathrm{rpm})$ at $4^{\circ} \mathrm{C}$. Pellets of nanocapsules thus obtained were then suspended in phosphate buffer $(\mathrm{pH}-7.4 ; 0.1 \mathrm{M})$ and each sample finally was lyophilized with mannitol $(2 \% \mathrm{~W} / \mathrm{V})$. The nanocapsules obtained were further dried by lyophilisation and they were applied on the cotton fabric by exhaustion method using $8 \%$ citric acid as binder. The fabric was finished according to the following recipe.M:L ratio $-1: 20$,Binder (Citric acid) $-8 \%$, Temperature $-55^{\circ} \mathrm{C}$, Time -30 mins, The antibacterial activity of the nanocapsules-finished fabric was determined by AATCC 147 test method.

\section{Results and Discussion}

\section{Collection of herbs and preparation of herbal extracts}

The herbs were collected from in and around Coimbatore district, identified and authenticated by the department of Botany, PSG College of arts and science college, Coimbatore. The plant parts were cleaned, processed and dried. The dried parts were powdered in mixie and the fine powder was extracted using methanol. The methanolic extract was filtered and the filtrate was dried to evaporate the solvent. Ricinus communis, Senna auriculata and Euphorbia hirta were screened for their antimicrobial efficiency and the combinations (1:3:2) [(5:15:10)] and the condition $20 \mathrm{kgf} / \mathrm{cm}^{2}$ Pressure, $20 \mathrm{~m} / \mathrm{min}$ rpm were standardized

\begin{tabular}{|c|c|c|c|c|}
\hline S. No & Parts used & $\begin{array}{c}\text { Common Name } \\
\text { (English) }\end{array}$ & $\begin{array}{c}\text { Common Name } \\
\text { (Tamil) }\end{array}$ \\
\hline 1 & $\begin{array}{c}\text { Ricinus } \\
\text { communis }\end{array}$ & Leaves & Castor oil plant & Amanakku \\
\hline 2 & $\begin{array}{c}\text { Senna } \\
\text { auriculata }\end{array}$ & Leaves & Ranawara & Avaram \\
\hline 3 & Euphorbia hirta & $\begin{array}{c}\text { Leaves, Stem } \\
\text { and Flower }\end{array}$ & Asthma weed & Amman pacharisi \\
\hline
\end{tabular}

Table 1: Plants used in the present study. 
Citation: Sumithra M, Vasugi Raaja N (2012) Antibacterial Efficacy Analysis of Ricinus communis, Senna auriculata and Euphorbia hirta Extract Treated on the Four Variant of Denim Fabric against Escherichia coli and Staphylococcus aureus. J Textile Sci Engg 2:111. doi:10.4172/21658064.1000111

for the selected herbs. These extract was used for finishing the herbal extract on the denim fabric.

Determination of the antibacterial activity of the finished fabric: The American Association of Textile Chemists and Colorists 147 method

From the Table 2 and Figure 1 shows that antibacterial activity in sample A, B, C and D. Comparison between the samples A, B, C and $D$ reveals that the finished sample was found to exhibit maximum zone of inhibition in sample D about $30 \mathrm{~mm}$ for Escherichia coli and $31 \mathrm{~mm}$ zone of inhibition for Staphylococcus aureus, when compared to other three fabrics. So the combination of $100 \%$ Cotton denim fabric shows better result. This fabric has higher rate of protection against the human pathogens than other three fabrics.

Determination of antibacterial activity for fabric finished by microencapsulated system

From the Table 3 and Figure 2 it is clearly shows that antibacterial activity in sample A, B, C and D. Comparison between the sample A, $\mathrm{B}, \mathrm{C}$ and D states that microencapsulated Denim D fabric has peak

\begin{tabular}{|c|c|c|c|}
\hline \multirow{2}{*}{ SI. No } & \multirow{2}{*}{ Samples } & \multicolumn{2}{|c|}{ Grow-free zone (mm) surrounding the sample } \\
\cline { 3 - 4 } & & Escherichia coli & Staphylococcus aureus \\
\hline 1 & Sample A & 29 & 29 \\
\hline 2 & Sample B & 30 & 30 \\
\hline 3 & Sample C & 29 & 30 \\
\hline 4 & Sample D & 30 & 31 \\
\hline
\end{tabular}

Table 2: Determination of the antibacterial activity of the finished fabric- The American Association of Textile Chemists and Colorists 147 method.
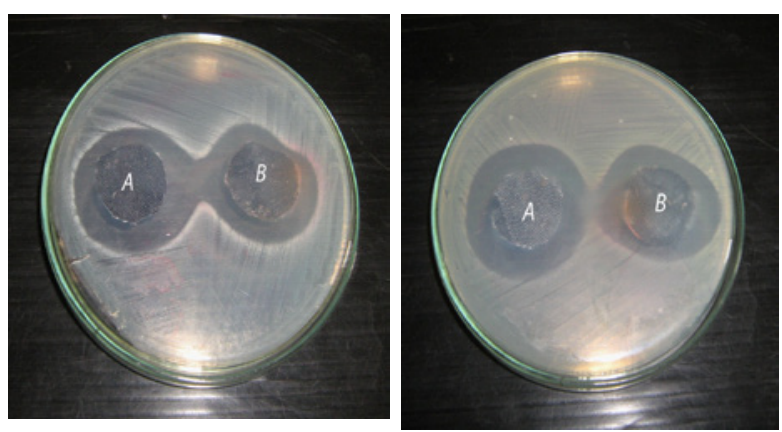

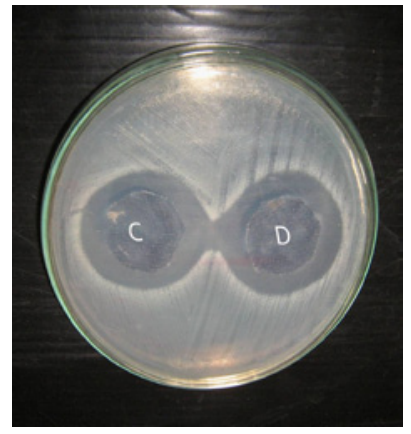

(a)

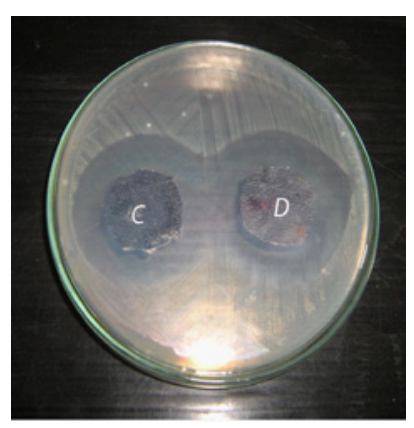

(b)
Figure 1: Photograph view of (a) Escherichia coli and (b) Staphylococcus aureus of the antibacterial activity of the finished fabric.

\begin{tabular}{|c|c|c|c|}
\hline \multirow{2}{*}{ SI. No } & \multirow{2}{*}{ Samples } & \multicolumn{2}{|c|}{ Grow-free zone $(\mathrm{mm})$ surrounding the sample } \\
\cline { 3 - 4 } & & Escherichia coli & Staphylococcus aureus \\
\hline 1 & Sample A & 32 & 39 \\
\hline 2 & Sample B & 29 & 28 \\
\hline 3 & Sample C & 25 & 28 \\
\hline 4 & Sample D & 42 & 73 \\
\hline
\end{tabular}

Table 3: Determination of antibacterial activity for fabric finished by microencapsulated system.
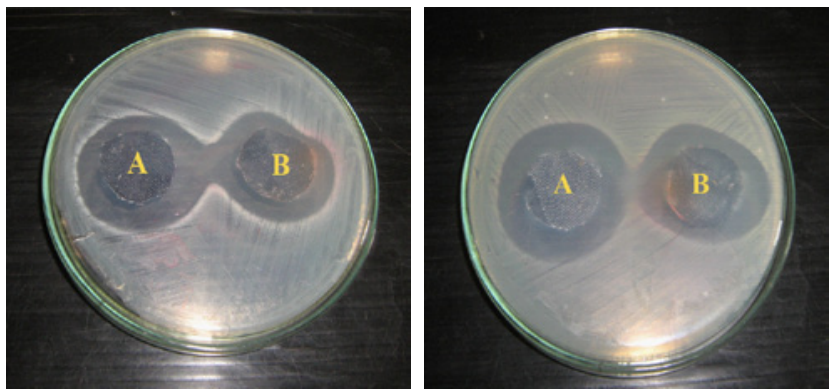

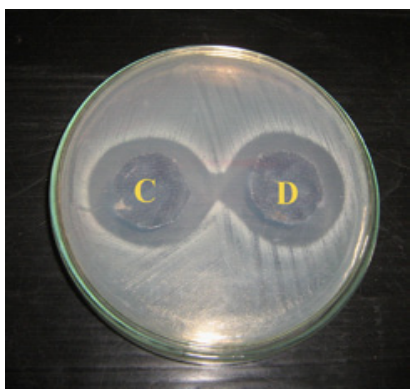

(a)

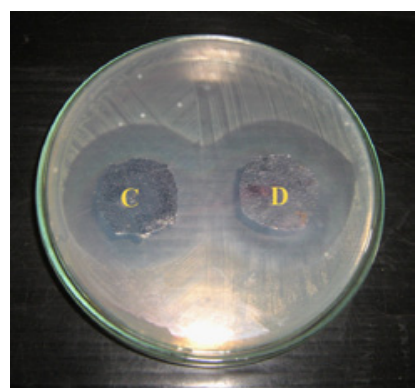

(b)
Figure 2: Photograph view of (a) Escherichia coli and (b) Staphylococcus aureus of the antibacterial activity of the finished fabric.

value when compared to other three fabrics. The results indicates the presence of clear zone of inhibition for treated fabrics against selected micro organism namely Staphylococcus aureus (gram positive) $73 \mathrm{~mm}$ and, Escherichia coli (gram negative) $42 \mathrm{~mm}$. So the $100 \%$ cotton denim fabric shows the more antimicrobial efficacy of micro encapsuled. As a result the microencapsulated herbal extracts uptake by the fabric has increased. These might be the reason for the increased bacterial reduction percentage of the finishes fabric.

Determination of antibacterial activity for fabric finished by nanoencapsulated system

From the Table 4 and Figure 3 it is clearly shows that antibacterial activity in sample A,B,C and D. Comparison among the sample A,B,C and $\mathrm{D}$ revels that nano encapsulated Denim $\mathrm{D}$ fabric has maximum value when compared to other three fabrics. It shows high percentage of reduction against both Staphylococcus aureus $35 \mathrm{~mm}$ and Escherichia coli $33 \mathrm{~mm}$ agent in the textile material. So the $100 \%$ cotton denim fabric shows better result. This fabric has higher rate of protection, avoid skin irritations, contols bad odour and kills pathogenic microorganisms.

\section{Conclusion}

This paper investigates the antimicrobial efficacy of three herbal 
Citation: Sumithra M, Vasugi Raaja N (2012) Antibacterial Efficacy Analysis of Ricinus communis, Senna auriculata and Euphorbia hirta Extract Treated on the Four Variant of Denim Fabric against Escherichia coli and Staphylococcus aureus. J Textile Sci Engg 2:111. doi:10.4172/21658064.1000111

\begin{tabular}{|c|c|c|c|}
\hline \multirow{2}{*}{ S. No. } & \multirow{2}{*}{ samples } & Grow-free zone (mm) surrounding the sample \\
\cline { 3 - 4 } & & Escherichia coli & Staphylococcus aureus \\
\hline 1 & Sample A & 22 & 28 \\
\hline 2 & Sample B & 20 & 24 \\
\hline 3 & Sample C & 15 & 17 \\
\hline 4 & Sample D & 33 & 35 \\
\hline
\end{tabular}

Table 4: Determination of antibacterial activity for fabric finished by nanoencapsulated system.
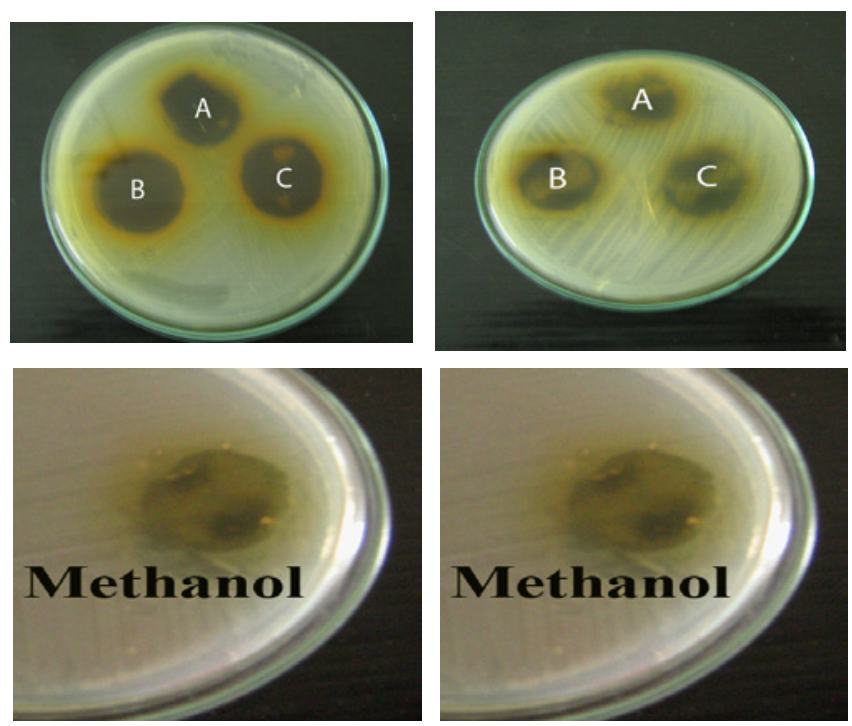

(a) (b)

Figure 3: Photograph view of (a) Escherichia coli and (b) Staphylococcus aureus of the antibacterial activity of the finished fabric(for methanol, D represent denim fabric).

extracts was studied. Further the treated cotton fabrics performance was evaluated using AATCC 147 Test Method. The results showed promising use of these herbal extracts as source of antimicrobial finishing on four variant of denim fabric. The extract finished fabric showed maximum antibacterial activity against both Escherichia coli and Staphylococcus aureus in Denim D fabric when compared to other three fabrics. The durability of the herbal finishing was increased by Micro encapsulation and Nano encapsulation methods.

\section{References}

1. Bhoomika GR, Ramesh GK, Anita MA (2007) A review. Pharmacognosy 1:143 149.

2. Thilagavathi G, Rajendrakumar K, Rajendran R (2005) Development of ecofriendly antimicrobial textile finishes using herbs. Indian Journal of Fibre \& Textile Research 30: 431-436.

3. Sivaramakrishnan CN (2007) Functional Finishes on Textiles by Mr Colourage

4. Barari M, Majidi RF, Madani M (2009) Preparation of Nanocapsules via emulsifier-free miniemulsion polymerization. J Nanosci Nanotech 9: 43484352.

5. Sunita D, Alka G (2007) Microencapsulation in textile processing: An Overview Asian Textile Journal 83.

6. Parthasarathi $V(2008)$ Nanotechnology adds value to textile finishing. The Indian Textile Journal.

7. Nayak R, Padhye R, Gon DP (2010) Sewing performance of stretch denim Journal of textile and apparel technology and management.

8. Vishwakarma S (2010) Quality Assurance in Denim Textile Review. 